\title{
Tissue Fluid Enzyme-Linked Immunosorbant Assay for Piglets Experimentally Infected with Toxoplasma gondii and Survey on Local and Imported Pork in Korean Retail Meat Markets
}

Won Gi Yoo ${ }^{1, \dagger}$, Sun-Min Kim², Tae Im Kim ${ }^{1,6}$, Jeong-Hee Han ${ }^{7}$, Dongmi Kwak ${ }^{8}$, Yun Sang Cho ${ }^{9}$, Seung-Won Kang ${ }^{10}$, Tong-Soo Kim ${ }^{12}$, Xing-Quan Zhu' ${ }^{13}$, Chunren Wang ${ }^{14}$, Heejeong Youn ${ }^{2, *}$, Sung-Jong Hong ${ }^{1, *}$

${ }^{1}$ Department of Medical Environmental Biology, Chung-Ang University College of Medicine, Seoul 06974, Korea; '2Department of Veterinary Parasitology, College of Veterinary Medicine, Seoul National University, Seoul 08826, Korea; ${ }^{3}$ Department of Parasitology and Tropical Medicine, Chonnam National University Medical School, Gwangju 61469, Korea; ${ }^{\circ}$ Department of Veterinary Parasitology, College of Veterinary Medicine, Jeju National University, Jeju 63243, Korea; ${ }^{5}$ Department of Parasitology, College of Medicine, Catholic University, Seoul 06591, Korea; ${ }^{6}$ Division of Planning and Management, Nakdong-gang National Institute of Biological Resources, Sangju 37242, Korea; ${ }^{7}$ Department of Veterinary Pathology, College of Veterinary Medicine and Institute of Veterinary Science, Kangwon National University, Chuncheon 24341, Korea; ${ }^{8}$ Department of Veterinary Parasitology, Kyungpook National University College of Veterinary Sciences, Daegu 41566, Korea; ${ }^{9}$ Parasitic and Insect Disease Laboratory, Bacterial and Parasitic Disease Division, Department of Animal and Plant Health Research, Animal and Plant Quarantine Agency, Gimcheon 39660, Korea; ${ }^{10}$ VexPert Co., Suwon 16614, Korea; ${ }^{11}$ KoreaBioGroup Co., Incheon 22013, Korea; ${ }^{12}$ Department of Parasitology and

Tropical Medicine and Inha Research Institute for Medical Sciences, Inha University School of Medicine, Incheon 22333, Korea; ${ }^{13}$ State Key

Laboratory of Veterinary Etiological Biology, Key Laboratory of Veterinary Parasitology of Gansu Province, Lanzhou Veterinary Research Institute, Chinese Academy of Agricultural Sciences, Lanzhou, Gansu 730046, P. R. China; ${ }^{14}$ Department of Preventive Veterinary Medicine, College of Animal Science and Veterinary Medicine, Heilongjiang Bayi Agricultural University, Daqing, Heilongjiang 163319, P. R. China; ${ }^{15}$ Department of Parasitology, Medical College of Soochow University, Suzhou, Jiangsu 215123, P. R. China

\begin{abstract}
To investigate the prevalence of Toxoplasma gondii in pork on the market in Korea, an in-house enzyme-linked immunosorbent assay for tissue fluid (CAU-tf-ELISA) was developed using a soluble extract of $T$. gondii RH strain tachyzoites. As the standard positive controls, the piglets were experimentally infected with $T$. gondii: Group A (1,000 cysts-containing bradyzoites), Group B (500 cysts-containing bradyzoites) and Group C (1.0 $\times 10^{3}$ or $1.0 \times 10^{4}$ tachyzoites). The CAU-tf-ELISA demonstrated infection intensity-dependent positivity toward tissue fluids with average cut-off value 0.15 : $100 \%$ for Group A, $93.8 \%$ for Group B and $40.6 \%$ for Group C. When tissue-specific cut-off values 0.0660.199 were applied, CAU-tf-ELISA showed $96.7 \%$ sensitivity, 100\% specificity, 100\% positive and $90.0 \%$ negative predictive values. When compared with the same tissue fluids, performance of CAU-tf-ELISA was better than that of a commercial ELISA kit. Of the 583 Korea domestic pork samples tested, anti-T. gondii antibodies were detected from $9.1 \%$ of whole samples and $37.9 \%$ from skirt meat highest among pork parts. In the 386 imported frozen pork samples, $1.8 \%$ (skirt meat and shoulder blade) were positive for anti-T. gondii antibodies. In Korea, prevalence of anti-T. gondii antibodies in the pork on retail markets appeared high, suggesting that regulations on pig farming and facilities are necessary to supply safe pork on the tables.
\end{abstract}

Key words: Toxoplasma gondii, ELISA, pork, tissue fluid, Korean, imported

\section{INTRODUCTION}

Toxoplasma gondii has been recognized as a protozoan of

- Received 27 September 2018, revised 18 October 2018, accepted 19 October 2018.

*Corresponding authors (hongsj@cau.ac.kr; younhj@snu.ac.kr)

†These authors contributed equally to this work.

(c) 2018, Korean Society for Parasitology and Tropical Medicine

This is an Open Access article distributed under the terms of the Creative Commons Attribution Non-Commercial License (http://creativecommons.org/licenses/by-nc/4.0) which permits unrestricted non-commercial use, distribution, and reproduction in any medium, provided the original work is properly cited. great medical relevance [1]. Although most human infections of T. gondii are asymptomatic or exhibit only mild symptoms, the infections can progress to a chronic phase, especially in the central nervous system. In immunocompromised individuals, T. gondii infection can also be reactivated and cause toxoplasmic lymphadenitis, meningoencephalitis, and/or ocular toxoplasmosis. In Europe, Australia, and North America, the prevalence of T. gondii antibody ranges from $37 \%$ to $58 \%$ among fertile women, whereas Southeast and East Asian countries 
have a relatively lower rate of infections [2]. In Korea, surveys on toxoplasmosis among various patient groups demonstrated a seroprevalence rate of 1.9-13.2\% [3-5]. Recently, the seroprevalence in Korean residents was reported to increase, reaching $13.2-25.8 \%$ [6-8], which is mainly attributed to the increased consumption of local or imported pork, or other animal meat at risk of $T$. gondii infection $[9,10]$. In this respect, it is necessary to establish comprehensive control measures to keep meat safe for human consumption [11].

Various diagnostic tools to detect T. gondii infection in pigs have been developed and applied, including enzyme-linked immunosorbent assay (ELISA) [12,13], latex agglutination test [14,15], modified agglutination test (MAT) [16,17], enzymelinked fluorescent assay [18], and polymerase chain reaction (PCR) [19]. ELISA could be a valuable tool to improve the surveillance and reporting system for $T$. gondii in animal populations in farms, contributing to keeping this zoonosis from becoming widespread [20]. In a zoonotic disease survey on pigs, ELISA was shown to be an effective and sensitive method for detecting T. gondii antibodies from tissue fluids, with relatively reduced effort, time, and cost in large-scale field surveys [21].

The aim of the present study was to develop a reliable tissue fluid-ELISA of Chung-Ang University (CAU-tf-ELISA) kit by employing standard positive controls from experimentally $T$. gondii-infected pigs as positive controls. The performance of the CAU-tf-ELISA kit was evaluated through comparison with a commercial kit, and both were used to survey the seroprevalence of anti-T. gondii antibodies in local and imported pork available in retail markets in Korea.

\section{MATERIALS AND METHODS}

\section{Parasites and animals}

Tachyzoites of the T. gondii RH strain were maintained by BALB/c mice passage (7-week-old female; Samtako BioKorea Inc., Osan, Seoul, Korea), with successful intraperitoneal inoculation of ascites (150-200 $\mu \mathrm{l} /$ mouse). The ascites containing tachyzoites were collected by peritoneal lavage using $2.5 \mathrm{ml}$ of Dulbecco's phosphate-buffered saline (DPBS; GIBCO, Grand Island, New York, USA) from the mice on the 5th day post-inoculation. The peritoneal fluid was centrifuged at 3,000 rpm at $4^{\circ} \mathrm{C}$ for $10 \mathrm{~min}$ and the purified tachyzoites were washed 3 times with $50 \mathrm{mM}$ PBS containing $1 \times$ Complete Mini, EDTA free (Roche, Mannheim, Germany). Bradyzoites were collected from the brain tissue samples of mice infected with the T. gon- dii ME49 strain according to the protocol previously described by Nam et al. [22].

All procedures and handling of piglets and mice were carried out in accordance with an Institutional Animal Care and Use Committee (IACUC) guidelines (established by The Animal and Plant Quarantine Agency, and The Ministry of Food and Drug Safety) for the care and use of laboratory animals. The experimental protocol for the present study was approved by the IACUC of Kangwon National University (Approval Number KW-130916-1). This included daily monitoring of the health of the experimental animals. Animals were cared by a large staff of highly qualified veterinarians, veterinary technicians, and animal caretakers. Serum samples were collected, and the piglets were autopsied at the Animal Hospital in the College of Veterinary Medicine, Kangwon National University, Chuncheon, Korea. For the detailed, see the Piglets infected with T. gondii experimentally' section.

\section{Piglets infected with $T$. gondii experimentally}

Thirteen siblings of 4-week-old piglets (Yorkshire Landrace D1 strain; XPbio, Ansung, Korea) were confirmed to be T. gondii-negative using the CAU-tf-ELISA kit (See details in the 'Preparation of CAU-tf-ELISA plates' section) and then delivered to the Medium Animal Laboratory in the College of Veterinary Medicine, Kangwon National University. For all experiments, animals were housed in groups in indoor facilities from time of inoculation until euthanasia. The piglets were divided into 3 groups as follows: Group A $(n=2)$ was infected by orally feeding 1,000 cysts (bradyzoites); Group B ( $\mathrm{n}=4$ ) was infected with 500 cysts; Group C ( $n=4)$ was injected with the tachyzoites ( 2 each with $1.0 \times 10^{3}$ and another 2 each with $1.0 \times 10^{4}$ ) of the T. gondii RH strain into the jugular vein using a syringe; and Group D ( $\mathrm{n}=3)$ as the normal control group, reared in an isolation ward.

The piglets were fed restricted food for 7 weeks, and the body temperature and weight were measured every week. Blood samples were taken from the jugular vein before the infection and every week thereafter. Sera were separated from the blood and kept at $-20^{\circ} \mathrm{C}$ until use. Seven weeks after infection, the piglets were autopsied at the Animal Hospital in the College of Veterinary Medicine, Kangwon National University. The internal organs (heart, lung, liver, tongue, and spleen) and parts of the pork such as the shoulder picnic, ham, belly, shoulder blade, skirt meat, loin, and tenderloin were resected and stored at $-20^{\circ} \mathrm{C}$ until use. 


\section{Preparation of CAU-tf-ELISA plates}

The tachyzoites were sonicated on ice in $0.1 \mathrm{ml}$ of $50 \mathrm{mM}$ PBS containing $1 \times$ Complete Mini for $5 \mathrm{~min}$. The homogenate was centrifuged at $13,000 \mathrm{rpm}$ at $4^{\circ} \mathrm{C}$ for $10 \mathrm{~min}$ and the supernatant was used as the crude antigen for ELISA. The protein concentration of the crude antigen was quantified using the Bio-Rad protein assay (Bio-Rad, Hercules, California, USA) and stored as aliquots at $-20^{\circ} \mathrm{C}$ until use. The crude antigen was diluted to $5 \mu \mathrm{g} / \mathrm{ml}$ with $0.05 \mathrm{M}$ carbonate buffer (pH 9.6). Twohundred microliters of the diluted antigen was added to each well of a 96-well plate and kept at $4^{\circ} \mathrm{C}$ overnight. The plate was then rinsed with $300 \mu$ of PBS/0.05\% Tween-20 (PBS/T) 3 times. Following steps were performed as described below.

\section{Optimization of the CAU-tf-ELISA kit}

Tissue fluids and serum samples collected from Group A ( $\mathrm{n}=18)$, Group B ( $\mathrm{n}=36)$, and Group C $(\mathrm{n}=36)$ were used as positive controls, and the samples from Group $D(n=27)$ were used as normal controls. The diagnostic performances (sensitivity, specificity, positive predictive value, and negative predictive value) of CAU-tf-ELISA were evaluated and compared with those of Toxoplasma commercial ELISA Kit S (hereafter referred to as Commercial kit S). For CAU-tf-ELISA, the tissue fluid and serum samples of the pigs were diluted with PBS/T at 1:100 and 1:10, respectively. Each sample was added to T. gondii antigen-coated wells $(200 \mu \mathrm{l} /$ well $)$ and incubated at $37^{\circ} \mathrm{C}$ for $1 \mathrm{hr}$. After rinsing with $250 \mu \mathrm{l}$ of PBS/T 3 times, a secondary antibody, $200 \mu$ of horseradish peroxidase-conjugated anti-swine IgG (Jackson ImmunoResearch Laboratories, West Grove, Pennsylvania, USA) (1:10,000 in PBS/T), was added and incubated at $37^{\circ} \mathrm{C}$ for $1 \mathrm{hr}$. After washing, $200 \mu \mathrm{l}$ of substrate buffer containing $0.01 \%$ o-phenylenediamine dihydrochloride and $0.025 \% \mathrm{H}_{2} \mathrm{O}_{2}$ was added to each well. The reaction was stopped with $25 \mu \mathrm{l}$ of $8 \mathrm{~N} \mathrm{H}_{2} \mathrm{SO}_{4}$. The optical density was measured at $490 \mathrm{~nm}\left(\mathrm{OD}_{490}\right)$ and recorded using a microplate reader (Molecular Devices, Sunnyvale, California, USA) [23]. The cut-off value was set with a value of mean \pm 2 standard deviations (SD) of Group D (normal control) for CAU-tf-ELISA. All ELISAs were independently repeated in quadruple. The ELISA using the Commercial kit $S$ was performed in accordance to the manufacturer's instruction, and the cut-off value of $\mathrm{OD}_{450}=0.3$ was applied as recommended by the manufacturer.

\section{Survey on local and imported pork using the CAU-tf- ELISA kit}

Local pork was surveyed for the antibodies against T. gondii at several markets in major cities of Korea, such as Seoul, Daejeon, Daegu, Busan, Gwangju, and Jeju. Twenty samples with 5 samples each of the heart, skirt meat, belly, loin, and shoulder picnic were purchased at retail meat shops. The pork loaves were transported to our lab of Chung-Ang University College of Medicine in coolers and stored at $-20^{\circ} \mathrm{C}$ until use.

The imported pork (pork belly, skirt meat, shoulder blade, and shoulder picnic) samples were purchased frozen from registered wholesale dealers in the local market. More than 20 packs (500 g per pack) of each part were purchased originating from several countries, including Austria, Belgium, USA, Chile, France, Hungary, Spain, the Netherlands, and Germany. The packed pork samples were transported and kept frozen until tested.

Tissue fluid samples were collected as described previously $[16,24,25]$. The frozen pork samples were thawed on the lab bench for $20 \mathrm{~min}$ at room temperature. The middle part (50 g) of the pork was cut out and stored at $4^{\circ} \mathrm{C}$ overnight in a zipperlocked plastic bag. The next morning, the liquid that oozed from the pork was transferred to a microfuge tube and spun at $13,000 \mathrm{rpm}$ at $4^{\circ} \mathrm{C}$ for $5 \mathrm{~min}$. The supernatant was collected and stored at $-20^{\circ} \mathrm{C}$ until analysis. Two tissue fluid samples each from each frozen pork sample were prepared independently.

\section{Statistical analysis}

Statistical analyses were performed using GraphPad Prism 5 software (GraphPad Software Inc., La Jolla, California, USA). Correlation between the values of $\mathrm{OD}_{450}$ measured using the 2 kits were assessed using the rho-squared test. The Kruskal-Wallis test or Mann-Whitney test was used to determine differences between the groups. Chi-squared or Fisher's exact tests were used to determine differences in the number or percentage of positivity between the groups. Differences were considered significant at $P<0.05$.

\section{RESULTS}

\section{Features of the standard positive controls}

In the piglets experimentally infected with T. gondii as the standard positive controls, the body temperature increased to $40.2^{\circ} \mathrm{C}$ for Group B from day 2, and to $39.6^{\circ} \mathrm{C}$ and $40^{\circ} \mathrm{C}$ for Group A and Group $C$ from day 5, respectively. From day 11 after infection, the increased body temperature subsided to the normal 
range. This febrile fluctuation after T. gondii administration proved that the piglets had acute toxoplasmosis and remained in a resilient/chronic phase $[26,27]$. This confirmed the successful establishment of the T. gondii-infected piglet groups as the standard positive controls using both bradyzoites and tachyzoites at 7 weeks.

In the sera of the standard positive controls, $T$. gondii-specific antibodies began to increase from 2 weeks and reached the peak level that was sustained during the infection. At the 7th week after infection, the titer of anti-T. gondii antibody was $0.56 \pm 0.32$ in Group A, $0.45 \pm 0.25$ in Group B, and $0.34 \pm 0.16$ in Group C (Fig. 1).

\section{Performance of CAU-tf-ELISA}

For the CAU-tf-ELISA, the overall cut-off value $\left(\mathrm{OD}_{490}\right)$ was determined to be 0.15 based on the assay on tissue fluids of all pork parts in the control piglets (Group D). The CAU-tfELISA demonstrated infection intensity-dependent positivity toward tissue fluids of the standard positive controls, with

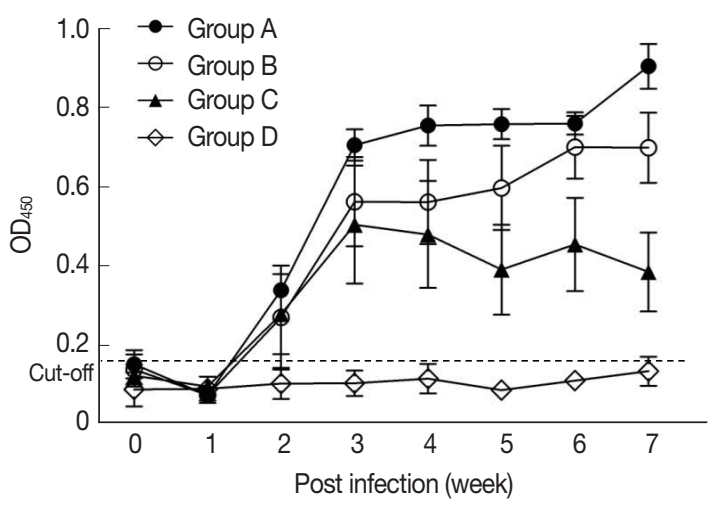

Fig. 1. Increase of anti-T. gondii antibodies in the sera of standard positive controls in the early phase of infection.
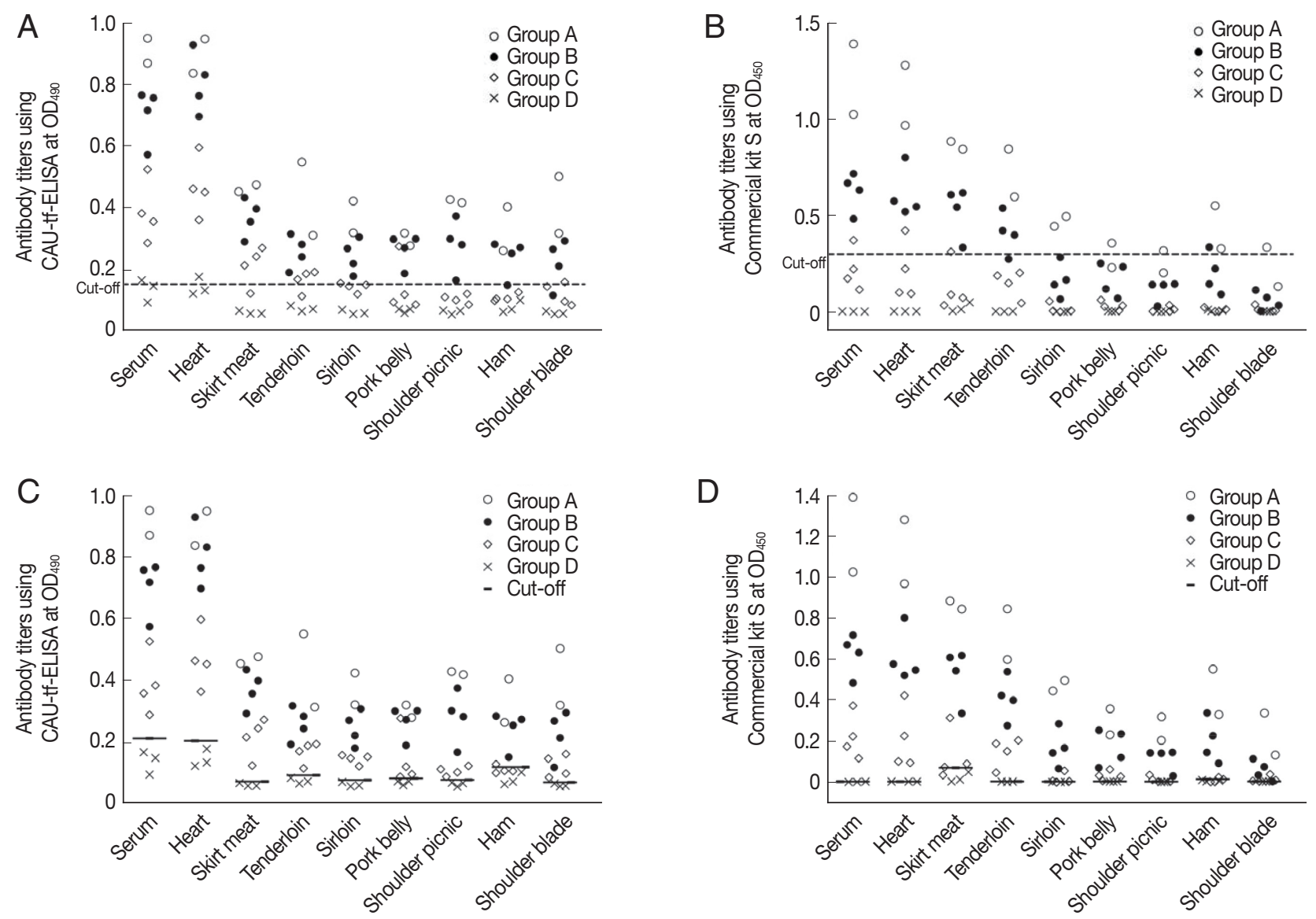

Fig. 2. Antibody titer of each part of the T. gondii-infected piglets using CAU-tf-ELISA kit and Commercial kit S. (A) The mean \pm 2 standard deviations of the antibody titer of Group D was designated as the cut-off value (0.15) for CAU-tf-ELISA. (B) The cut-off value (0.3) for the $\mathrm{OD}_{450}$ was used for the Commercial kit $\mathrm{S}$ according to the manufacturer's guideline. Tissue-specific cut-off values were applied for CAU-tf-ELISA (C) and Commercial kit S (D) according to each meat portion (See the details in Table 3). 
$100 \%$ positivity detected due to heavy infection (Group A), 93.8\% due to moderate infection (Group B), and 40.6\% due to light infection (Group C) (Fig. 2A; Table 1). The positive rates of the pork varied according to the parts of the meat as follows: $100 \%$ for the serum and heart, $90.0 \%$ for skirt meat and tenderloin, $70.0 \%$ for loin and pork belly, $60.0 \%$ for shoulder picnic and shoulder blade, and 50.0\% for ham of the standard positive controls. The Commercial kit $\mathrm{S}$, with a cutoff value $\left(\mathrm{OD}_{450}\right)$ fixed at 0.3 , showed lower positivity rates overall, with half the rate detected using the CAU-tf-ELISA (Fig. 2B; Table 1). As shown in Table 2, the overall diagnostic performance of CAU-tf-ELISA was better than that of the Commercial kit $S$ in terms of sensitivity, specificity, positive predictive value, and negative predictive value.
When tissue-specific cut-off values of 0.066-0.199 were applied according to each meat portion, the CAU-tf-ELISA detected anti-T. gondii antibodies from almost all of the tissue fluids, showing positivity in $96.3 \%$ of the pork from standard positive controls, with no antibodies detected in the normal control group piglets. The Commercial kit S showed a similar, but lower, rate of antibody detection (91.3\%) but also showed cross-reactivity to the tissue fluids (12.5\%) of the normal control group piglets (Figs. 2C\&D; Table 3). The diagnostic performance was very good, with high values of sensitivity, specificity, positive predictive value, and negative predictive value (Table 2). The performance correlation between the CAU-tfELISA kit and Commercial kit $S$ was evaluated in terms of the $\mathrm{OD}_{490}$ values. The CAU-tf-ELISA results were correlated with

Table 1. Comparison of the functionality of CAU-tf-ELISA kit and Commercial kit S for tissue fluids samples from the standard positive controls

\begin{tabular}{|c|c|c|c|c|c|c|c|c|c|c|}
\hline \multirow{3}{*}{ Pork Part } & \multicolumn{10}{|c|}{ No. of positive samples (\%) } \\
\hline & \multicolumn{2}{|c|}{ Group A } & \multicolumn{2}{|c|}{ Group B } & \multicolumn{2}{|c|}{ Group C } & \multicolumn{2}{|c|}{ Subtotal (Groups A-C) } & \multicolumn{2}{|c|}{ Group D } \\
\hline & $\begin{array}{l}\text { CAU-tf- } \\
\text { ELISA }\end{array}$ & $\begin{array}{l}\text { Commercial } \\
\text { kit S }\end{array}$ & $\begin{array}{l}\text { CAU-tf- } \\
\text { ELISA }\end{array}$ & $\begin{array}{l}\text { Commercial } \\
\text { kit S }\end{array}$ & $\begin{array}{l}\text { CAU-tf- } \\
\text { ELISA }\end{array}$ & $\begin{array}{l}\text { Commercial } \\
\text { kit S }\end{array}$ & $\begin{array}{l}\text { CAU-tf- } \\
\text { ELISA }\end{array}$ & $\begin{array}{l}\text { Commercial } \\
\text { kit S }\end{array}$ & $\begin{array}{l}\text { CAU-tf- } \\
\text { ELISA }\end{array}$ & $\begin{array}{c}\text { Commercial } \\
\text { kit S }\end{array}$ \\
\hline Heart & $2(100)$ & $2(100)$ & $4(100)$ & $4(100)$ & $4(100)$ & $1(25.0)$ & $10(100)$ & $7(70.0)$ & $1(33.3)$ & $0(0.0)$ \\
\hline Skirt meat & $2(100)$ & $2(100)$ & $4(100)$ & $4(100)$ & $3(75.0)$ & $1(25.0)$ & $9(90.0)$ & $7(70.0)$ & $0(0.0)$ & $0(0.0)$ \\
\hline Tenderloin & $2(100)$ & $2(100)$ & $4(100)$ & $3(75.0)$ & $3(75.0)$ & $0(0.0)$ & $9(90.0)$ & $5(50.0)$ & $0(0.0)$ & $0(0.0)$ \\
\hline Sirloin & $2(100)$ & $2(100)$ & $4(100)$ & $0(0.0)$ & $1(25.0)$ & $0(0.0)$ & $7(70.0)$ & $2(20.0)$ & $0(0.0)$ & $0(0.0)$ \\
\hline Pork belly & $2(100)$ & $1(50.0)$ & $4(100)$ & $0(0.0)$ & $1(25.0)$ & $0(0.0)$ & $7(70.0)$ & $1(10.0)$ & $0(0.0)$ & $0(0.0)$ \\
\hline Shoulder picnic & $2(100)$ & $1(50.0)$ & $4(100)$ & $0(0.0)$ & $0(0.0)$ & $0(0.0)$ & $6(60.0)$ & $1(10.0)$ & $0(0.0)$ & $0(0.0)$ \\
\hline Ham & $2(100)$ & $2(100)$ & $3(75.0)$ & $1(25.0)$ & $0(0.0)$ & $0(0.0)$ & $5(50.0)$ & $3(30.0)$ & $0(0.0)$ & $0(0.0)$ \\
\hline Shoulder blade & $2(100)$ & $1(50.0)$ & $3(75.0)$ & $0(0.0)$ & $1(25.0)$ & $0(0.0)$ & $6(60.0)$ & $1(10.0)$ & $0(0.0)$ & $0(0.0)$ \\
\hline Total & $16(100)$ & 13 (81.3) & 30 (93.8) & $12(37.5)$ & $13(40.6)$ & $2(6.3)$ & 59 (73.8) & 27 (33.8) & $1(3.3)$ & $0(0.0)$ \\
\hline Serumb & $2(100)$ & $2(100)$ & $4(100)$ & $4(100)$ & $4(100)$ & $1(25.0)$ & $10(100)$ & 7 (70.0) & $1(3.3)$ & $0(0.0)$ \\
\hline
\end{tabular}

aPositive rate (\%) was determined by a cut-off value of 0.15 for the CAU-tf-ELISA kit and 0.3 for the Commercial kit S.

${ }^{\mathrm{b}}$ As supporting data.

Table 2. Diagnostic performance of the CAU-tf-ELISA kit and Commercial kit S in terms of detection of anti-T. gondii antibodies

\begin{tabular}{|c|c|c|c|c|c|c|c|c|}
\hline \multirow[b]{2}{*}{ ELISA (cut-off value) } & \multirow[b]{2}{*}{ Results } & \multicolumn{3}{|c|}{ No. of specimens with } & \multicolumn{4}{|c|}{ Diagnostic performance [95\% confidence interval] } \\
\hline & & Positive & Negative & Subtotal & Sensitivity & Specificity & $\begin{array}{c}\text { Positive } \\
\text { predictive value }\end{array}$ & $\begin{array}{c}\text { Negative } \\
\text { predictive value }\end{array}$ \\
\hline \multirow[t]{3}{*}{ CAU-tf-ELISA (0.15) } & Positive & 69 & 2 & 71 & & & & \\
\hline & Negative & 21 & 25 & 46 & & & & \\
\hline & Subtotal & 90 & 27 & 117 & $\begin{array}{c}76.70 \% \\
{[66.6 \% \text { to } 84.9 \%]}\end{array}$ & $\begin{array}{c}92.60 \% \\
{[75.7 \% \text { to } 99.1 \%]}\end{array}$ & $\begin{array}{c}97.20 \% \\
{[90.1 \% \text { to } 99.3 \%]}\end{array}$ & $\begin{array}{c}54.40 \% \\
{[44.6 \% \text { to } 63.7 \%]}\end{array}$ \\
\hline \multirow[t]{3}{*}{ Commercial kit S (0.3) } & Positive & 34 & 0 & 34 & & & & \\
\hline & Negative & 56 & 27 & 83 & & & & \\
\hline & Subtotal & 90 & 27 & 117 & $\begin{array}{c}37.80 \% \\
{[27.8 \% \text { to } 48.6 \%]}\end{array}$ & $\begin{array}{c}100 \% \\
{[87.2 \% \text { to } 100 \%]}\end{array}$ & $100 \%$ & $\begin{array}{c}32.50 \% \\
\text { [29.1\% to } 36.2 \% \text { ] }\end{array}$ \\
\hline \multirow{3}{*}{$\begin{array}{l}\text { CAU-tf-ELISA } \\
\text { (tissue-specific values) }\end{array}$} & Positive & 87 & 0 & 87 & & & & \\
\hline & Negative & 3 & 27 & 30 & & & & \\
\hline & Subtotal & 90 & 27 & 117 & $\begin{array}{c}96.70 \% \\
{[90.6 \% \text { to } 99.3 \%]}\end{array}$ & $\begin{array}{c}100 \% \\
{[87.2 \% \text { to } 100 \%]}\end{array}$ & $100 \%$ & $\begin{array}{c}90.00 \% \\
{[74.7 \% \text { to } 96.5 \%]}\end{array}$ \\
\hline
\end{tabular}


those of the Commercial kit $S$ with a correlation co-efficient $\left(r^{2}\right)$ of 0.7504 in Group A, 0.6463 in Group B, 0.6755 in Group C, and 0.7016 in whole standard positive controls (Fig. 3).

\section{Pork on the Korean markets}

In Korea, the local pork available on the retail market in- cludes pork belly, the most popular, shoulder picnic and loin, and visceral appendages, including the heart and skirt meat. A total of 604 local pork samples were collected from 6 major cities across Korea. Tissue fluids were collected from 583 local pork samples, which revealed $9.1 \%$ positivity for anti-T. gondii antibodies (Table 4). Of the 53 antibody-positive local sam-

Table 3. Functionality of CAU-tf-ELISA kit and Commercial kit S applied with tissue-specific cut-off values

\begin{tabular}{|c|c|c|c|c|c|c|}
\hline \multirow{3}{*}{ Pork Part } & \multicolumn{3}{|c|}{ CAU-tf-ELISA } & \multicolumn{3}{|c|}{ Commercial kit S } \\
\hline & \multirow{2}{*}{ Cut-off value } & \multicolumn{2}{|c|}{ No. of positive (\%) } & \multirow{2}{*}{ Cut-off value } & \multicolumn{2}{|c|}{ No. of positive (\%) } \\
\hline & & Groups A-C & Group D & & Groups A-C & Group D \\
\hline Heart & 0.199 & $10(100)$ & $0(0.0)$ & 0.005 & $10(100)$ & 2 (66.6) \\
\hline Skirt meat & 0.068 & $10(100)$ & $0(0.0)$ & 0.072 & $9(90.0)$ & $0(0.0)$ \\
\hline Tenderloin & 0.088 & $10(100)$ & $0(0.0)$ & 0.006 & $10(100)$ & $0(0.0)$ \\
\hline Sirloin & 0.073 & $10(100)$ & $0(0.0)$ & 0.005 & $9(90.0)$ & $0(0.0)$ \\
\hline Belly & 0.079 & $10(100)$ & $0(0.0)$ & 0.006 & $10(100)$ & $0(0.0)$ \\
\hline Shoulder picnic & 0.074 & $10(100)$ & $0(0.0)$ & 0.005 & $9(90.0)$ & $1(33.3)$ \\
\hline Ham & 0.115 & 7 (70.0) & $0(0.0)$ & 0.016 & $7(70.0)$ & $0(0.0)$ \\
\hline Shoulder blade & 0.066 & $10(100)$ & $0(0.0)$ & 0.006 & $9(90.0)$ & $0(0.0)$ \\
\hline Total & & 77 (96.3) & $0(0.0)$ & & 73 (91.3) & $43(12.5)$ \\
\hline Serum ${ }^{a}$ & 0.207 & $10(100)$ & $0(0.0)$ & 0.005 & $10(100)$ & 1 (33.3) \\
\hline
\end{tabular}

${ }^{a}$ As supporting data.
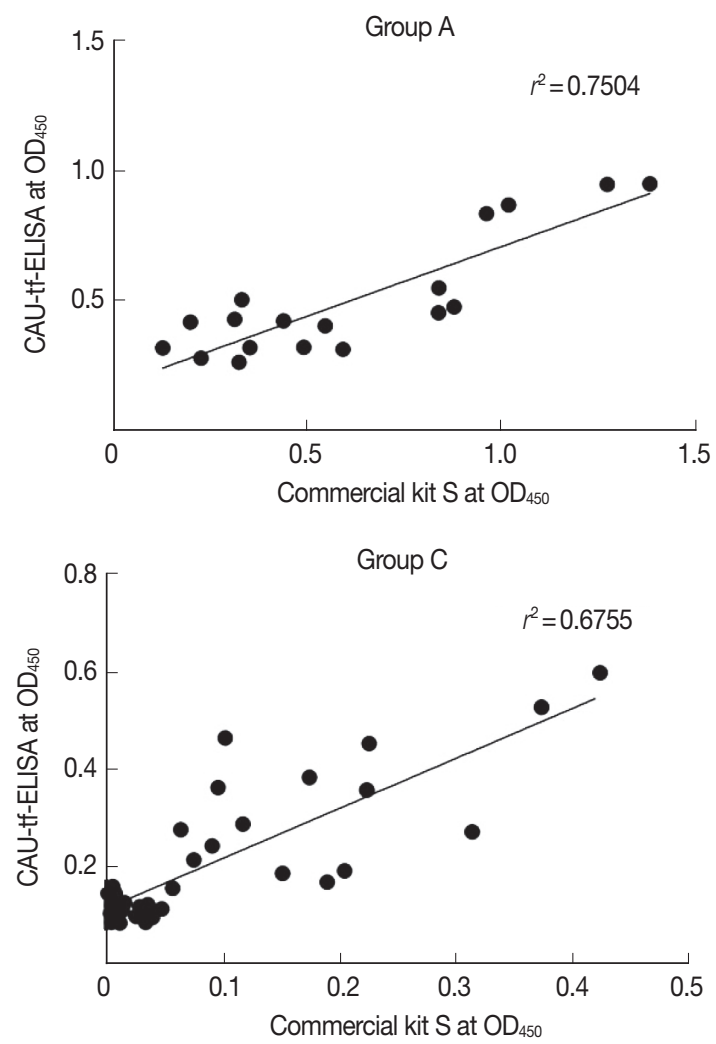
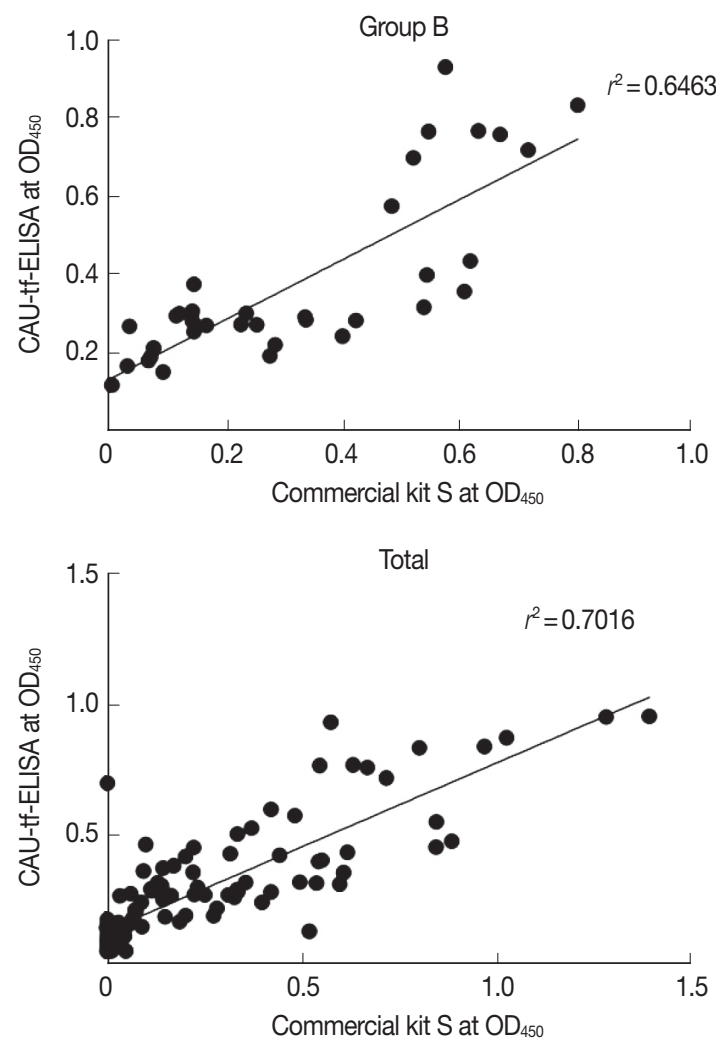

Fig. 3. Correlation between T. gondii antibody levels of the standard positive controls assayed using the CAU-tf-ELISA kit and Commercial kit S. 
ples, 44 were skirt meat, 8 were hearts, and one was pork belly. All of the shoulder picnics and loins were negative for T. gondii. Anti-T. gondii antibody positive-pork samples were detected in all 6 cities sampled. The positive rate of anti-T. gondii antibodies ranged from $2.0 \%$ in Seoul to $15.5 \%$ in Busan. The skirt meat was found to be positive for the antibody in all cities, the heart was positive in 4 cities, and pork belly was positive in only one city (Table 5).

For the foreign pork, a total of 390 frozen pork samples collected were imported from several countries in North America, Central and South America, and Europe. Of the foreign pork samples, $1.8 \%$ (7/386) were positive for anti-T. gondii antibodies. The skirt meat and shoulder blade imported from Mexico and Spain were antibody-positive (Table 4).

Table 4. Prevalence of anti-T. gondii antibodies in the tissue fluid of local and imported pork determined by CAU-tf-ELISA

\begin{tabular}{|c|c|c|c|}
\hline \multirow{2}{*}{ Pork } & \multicolumn{2}{|c|}{ No. of samples collected } & \multirow{2}{*}{ Positivity (\% } \\
\hline & Meat & Tissue fluid & \\
\hline \multicolumn{4}{|l|}{ Local } \\
\hline Skirt meat & 120 & 116 & $44(37.9)$ \\
\hline Heart & 120 & 120 & $8(6.7)$ \\
\hline Belly & 124 & 117 & $1(0.9)$ \\
\hline Shoulder picnic & 120 & 113 & $0(0.0)$ \\
\hline Loin & 120 & 117 & $0(0.0)$ \\
\hline Subtotal & 604 & 583 & $53(9.1)$ \\
\hline \multicolumn{4}{|l|}{ Imported (Country) } \\
\hline Belly ${ }^{a}$ & 186 & 183 & $0(0.0)$ \\
\hline Skirt meat (Mexico) & 20 & 20 & $2(10.0)$ \\
\hline Skirt meat (Canada) & 20 & 20 & $0(0.0)$ \\
\hline Skirt meat (France) & 20 & 20 & $0(0.0)$ \\
\hline Shoulder picnic (USA) & 22 & 22 & $0(0.0)$ \\
\hline Shoulder blade (Chile) & 62 & 62 & $0(0.0)$ \\
\hline Shoulder blade (Mexico) & 50 & 49 & $4(8.2)$ \\
\hline Shoulder blade (Spain) & 10 & 10 & $1(10.0)$ \\
\hline Subtotal & 390 & 386 & $7(1.8)$ \\
\hline Total & 994 & 969 & $60(6.2)$ \\
\hline
\end{tabular}

aTwenty imported pork belly samples analyzed from Austria, Belgium, USA, Chile, France, Hungary, the Netherlands, and Spain each, and 26 samples from Germany were analyzed.

\section{DISCUSSION}

The consumption of pork has been increasing annually in Korea along with socio-economic development and Westernlike changes in dietary and lifestyle habits. Any part of the $T$. gondii-infected pork can be considered as a main source of human infection, since T. gondii has been found in most portions of the meat $[9,10,28]$. However, it is hard to find information on the extent of contamination of T. gondii tachyzoites and/or bradyzoites in pork on the retail market in Korea.

ELISA is one of the most reliable diagnostic methods to estimate the seroprevalence of toxoplasmosis [25,29]. It precisely assays IgG, IgM, IgA, and IgE antibodies. To support accurate serological interpretation and further assay optimization, it is important to establish proper positive controls $[16,25,26,30]$. Practically, naturally T. gondii-infected pigs are good references. However, the results can neither be accurately quantified nor interpreted since information on the parasite burden and infection date is scarce. For this purpose, we established experimentally $T$. gondii-infected piglets as standard positive controls. High antibody levels were maintained in all experimental groups infected with either bradyzoites or tachyzoites. Based on the standard positive controls, the CAU-tf-ELISA kit was developed in-house using the crude antigen of the T. gondii RH strain tachyzoites. Whole tachyzoite antigen has been reported to act as a good antigen since it showed higher relative sensitivity in ELISA than in the MAT $[20,24,25]$. Tissue fluid samples can be useful for the routine diagnosis of $T$. gondii infection since they can be obtained at slaughter houses. Moreover, strong correlations between tissue fluids and sera were reported in ELISAs [12,31]. Among the standard positive controls, Group A piglets showed the highest antibody titer $(0.56 \pm 0.32)$ although the piglets of Groups $B$ and $C$ had severe acute febrile illness. Based on the standard positive controls, the CAU-tf-ELISA kit exhibited better sensitivity and negative predictive values

Table 5. Prevalence of T. gondii antibodies in the tissue fluid of local pork using CAU-tf-ELISA according to the surveyed region

\begin{tabular}{|c|c|c|c|c|c|c|c|c|}
\hline \multirow{2}{*}{ Pork } & \multirow{2}{*}{ No. examined } & \multicolumn{7}{|c|}{ No. of positive samples (\%) } \\
\hline & & Seoul & Daejeon & Daegu & Busan & Gwangju & Jeju & Subtotal \\
\hline Skirt & 116 & $2(10.0)$ & $3(15.8)$ & $10(58.8)$ & $12(60.0)$ & $6(30.0)$ & $11(55.0)$ & $44(37.9)$ \\
\hline Heart & 120 & $0(0.0)$ & $0(0.0)$ & $3(15.0)$ & $3(15.0)$ & $1(5.0)$ & $1(5.0)$ & $8(6.7)$ \\
\hline Belly & 117 & $0(0.0)$ & $1(5.0)$ & $0(0.0)$ & $0(0.0)$ & $0(0.0)$ & $0(0.0)$ & $1(0.9)$ \\
\hline Shoulder picnic & 113 & $0(0.0)$ & $0(0.0)$ & $0(0.0)$ & $0(0.0)$ & $0(0.0)$ & $0(0.0)$ & $0(0.0)$ \\
\hline Loin & 117 & $0(0.0)$ & $0(0.0)$ & $0(0.0)$ & $0(0.0)$ & $0(0.0)$ & $0(0.0)$ & $0(0.0)$ \\
\hline Total & 583 & $2(2.0)$ & $4(4.0)$ & $13(15.1)$ & $15(15.5)$ & $7(7.0)$ & $12(11.9)$ & $53(9.1)$ \\
\hline
\end{tabular}


than the Commercial kit S. Different antibody titers among Groups A, B, and C are associated with the pathogenicity of $T$. gondii strains and the infection dose [32].

In our study, antibody-positive rates were different according to the tissue fluids obtained from different parts of the pork. In the CAU-tf-ELISA tests, the heart, skirt meat, and tenderloin showed high positivity rates at more than $90 \%$, whereas the other parts presented moderate (sirloin and pork belly) to low (shoulder picnic, ham, and shoulder blade) positivity rates. Fundamentally, the level of antibody in tissue fluids could be affected and dependent on the blood supply and cellular density of the tissues $[33,34]$. The organs with high tissue density that undergo continuous movement, such as the heart and skirt muscle, could be expected to show relatively higher antibody positivity. Moreover, positive rates can be different between experimentally and naturally infected pork [20].

The in-house CAU-tf-ELISA kit manufactured using these well-designed positive controls produced better sensitivity and negative predictive values than the Commercial kit S. Different cut-off values, 0.15 for the CAU-tf-ELISA kit and 0.3 for the Commercial kit $\mathrm{S}$, might have influenced the results of diagnostic performance. This is consistent with previous findings [35], in which the authors compared 4 commercial ELISA kits for detectability of anti-T. gondii antibodies in the meat fluid of slaughtered pigs using MAT as a reference. The use of cut-off values $(0.07-0.50)$ other than the thresholds preset by the manufacturers produced the highest accuracy.

To overcome the limitation of the fixed cut-off value and the heterogeneity of source tissues, we applied tissue-specific cutoff values for both kits. Tissue-specific cut-off values (0.0660.199) of the CAU-tf-ELISA improved diagnostic performances, with all samples being positive (100\%) except for ham samples. Application of tissue-specific cut-off values is therefore significantly useful for the more sensitive detection of anti-T. gondii antibodies in the tissue fluids. Unfortunately, there is no evidence related to the seroprevalence for ham (or thigh) samples of pigs.

The Korean local pork in retail markets showed a 9.1\% positive rate for anti-T. gondii antibodies in this study, reflecting a decline in prevalence during the last 5 decades, reported at 10$58.6 \%$ in the 1980 s [32,36] and $16.8 \%$ in 2009 [36]. This decrease could be attributed to less exposure to typical $T$. gondii infection sources which are improvement of pig farming facilities and strengthened regulations. Nevertheless, anti-T. gondii antibody was still detected in over $12 \%$ of the pork samples collected from Busan, Daegu, and Jeju. When focused on skirt meat, more than half of the pork samples collected in these 3 cities were found to be positive for anti-T. gondii antibodies. As for the seroprevalence of toxoplasmosis in the residents of Korea, anti-T. gondii antibody-positive rates doubled from $5.8 \%$ in 1989 to $11.3-13.2 \%$ in 2011 on Jeju Island. The rates increased more steeply from $1.9 \%$ in 1989 to $8.0 \%$ in 2010 in Seoul. In the early 2010s, the seroprevalence was found to be $14.7-19.3 \%$ in 2010 and increased to $26.8-32.1 \%$ in 2013 in northern counties of Gyeonggi-do, close to the demilitarized zone, at the Midwest region of the Korea peninsula $[3,6,8,13,37]$. Although the seroprevalence has been decreasing in pigs, the prevalence of human toxoplasmosis has been increasing in recent years. This surge of human toxoplasmosis could be linked to the increased consumption of undercooked pork infected with $T$. gondii $[9,10]$. Thus, prevention and control action/measures for swine toxoplasmosis should be enacted to block the pigs exposed to $T$. gondii infection sources (i.e., cat feces and infected rodents) in the farms $[31,38]$. These actions should also include control measures on feral cats, since the seroprevalence of anti-T. gondii antibodies was recently shown to be high reaching up to $50 \%$ in urban and rural areas in Korea [39].

Only some imported pork samples appeared to be positive for anti-T. gondii antibodies in the shoulder blade and skirt meat from 2 countries. This finding might reflect the prevalence of the anti-T. gondii antibodies in the pigs in these 2 countries: $11.2 \%$ in Mexico [40] and 3.4\% in Spain [41]. The seroprevalence of anti-T. gondii antibodies was reported to be $2.6 \%$ in pigs on farms in the USA [42], 2.7\% in France [43], and $8.8 \%$ in Chile [44]. There were some differences in the anti-T. gondii antibody prevalence among the imported pork and pig-raising countries. This difference could be dependent on the sample collection, including the age of the pigs and the portions of the pork, and which assay was employed. Most of these reports from other countries largely investigated the belly and shoulder of the pork. These pork samples of the standard positive controls analyzed in the present study revealed lower sensitivity for anti-T. gondii antibodies compared to those of the heart, skirt, and tenderloin. In the cases of serum antibodypositive samples, the bradyzoites and/or tachyzoites of $T$. gondii could be present in the tissues of the pigs. To import safe pork without T. gondii contamination, the pigs should first be tested for the presence of $T$. gondii antibodies in the serum before being slaughtered in their home country. Therefore, the government should take actions for health education to pre- 
vent human infection from contaminated pork and meat, such as hygiene, proper cooking temperatures, and other methods to inactivate T. gondii cysts in meat [11].

A limitation of our study is the small number of piglets experimentally infected with T. gondii and normal controls although our samples were the various tissue fluids obtained from different parts of the piglets. Moreover, our results were not confirmed by bioassay [12] or PCR [19] and thus parasite density was not presented.

In conclusion, an in-house tissue fluid-ELISA kit (CAU-tfELISA) was developed employing experimentally T. gondii-infected piglets as the standard positive controls and was further optimized using tissue-specific cut-off values. The CAU-tf-ELISA kit is suggested to be practically useful for detection of $T$. gondii in various tissue fluids from the pork and sera for individual diagnosis as well as for surveillance on $T$. gondii infections. In this survey using CAU-tf-ELISA, the seroprevalence of anti-T. gondii antibodies was found to be $9.1 \%$ in the local pork and $1.8 \%$ in the imported foreign pork across retail markets in Korea. Thus, from a public health point of view, it is necessary to establish regulatory actions and control measures against foodborne toxoplasmosis in Korea.

\section{ACKNOWLEDGMENT}

This research was supported by a grant (Project Code No. Z-1541778-2013-14-01) from Research of Animal and Plant Quarantine Agency, South Korea.

\section{CONFLICT OF INTEREST}

We have no conflict of interest related to this study.

\section{REFERENCES}

1. Hill DE, Chirukandoth S, Dubey JP. Biology and epidemiology of Toxoplasma gondii in man and animals. Anim Health Res Rev 2005; 6: 41-61.

2. Robert-Gangneux F, Dardé ML. Epidemiology of and diagnostic strategies for toxoplasmosis. Clin Microbiol Rev 2012; 25: 264296.

3. Choi WY, Nam HW, Youn JH, Kim WS, Kim WK. Toxoplasma antibody titers by indirect latex agglutination test in patients of Kangnam St. Mary's Hospital and Cheju Medical Center. Korean J Prasitol 1989; 27: 171-175.

4. Choi WY, Nam HW, Youn JH, Kim DJ, Kong Y, Kang SY, Cho SY.
Detection of antibodies in serum and cerebrospinal fluid to Toxoplasma gondii by indirect latex agglutination test and enzymelinked immunosorbent assay. Korean J Prasitol 1992; 30: 83-90.

5. Song KJ, Shin JC, Shin HJ, Nam HW. Seroprevalence of toxoplasmosis in Korean pregnant women. Korean J Parasitol 2005; 43: 69-71.

6. Hong SJ, Chong CK, Lee K, Kim TS, Hong YP, Ahn HJ, Kim HY, Ko AR, Kim YJ, Nam HW. Maintained seroprevalence of toxoplasmosis among the residents of Jeju island, Korea. Korean J Parasitol 2011; 49: 309-311.

7. Ahn HJ, Cho PY, Ahn SK, Kim TS, Chong CK, Hong SJ, Cha SH, Nam HW. Seroprevalence of toxoplasmosis in the residents of Cheorwon-gun, Gangwon-do, Korea. Korean J Parasitol 2012; 50: 225-227.

8. Yang Z, Cho PY, Ahn SK, Ahn HJ, Kim TS, Chong CK, Hong SJ, Cha SH, Nam HW. A surge in the seroprevalence of toxoplasmosis among the residents of islands in Gangwha-gun, Incheon, Korea. Korean J Parasitol 2012; 50: 191-197.

9. Djurković-Djaković O, Bobić B, Nikolić A, Klun I, Dupouy-Camet J. Pork as a source of human parasitic infection. Clin Microbiol Infect 2013; 19: 586-594.

10. Hill DE, Dubey JP. Toxoplasma gondii prevalence in farm animals in the United States. Int J Parasitol 2013; 43: 107-113.

11. Jones JL, Dubey JP. Foodborne toxoplasmosis. Clin Infect Dis 2012; 55: 845-851.

12. Wingstrand A, Lind P, Haugegaard J, Henriksen SA, Bille-Hansen V, Sorensen V. Clinical observations, pathology, bioassay in mice and serological response at slaughter in pigs experimentally infected with Toxoplasma gondii. Vet Parasitol 1997; 72: 129-140.

13. Lim H, Lee SE, Jung BK, Kim MK, Lee MY, Nam HW, Shin JG, Yun $\mathrm{CH}$, Cho HI, Shin EH, Chai JY. Serologic survey of toxoplasmosis in Seoul and Jeju-do, and a brief review of its seroprevalence in Korea. Korean J Parasitol 2012; 50: 287-293.

14. Fan CK, Su KE, Tsai YJ. Serological survey of Toxoplasma gondii infection among slaughtered pigs in northwestern Taiwan. J Parasitol 2004; 90: 653-654.

15. Han K, Shin DW, Lee TY, Lee YH. Seroprevalence of Toxoplasma gondii infection and risk factors associated with seropositivity of pregnant women in Korea. J Parasitol 2008; 94: 963-965.

16. Forbes LB, Parker SE, Gajadhar AA. Performance of commercial ELISA and agglutination test kits for the detection of anti-Toxoplasma gondii antibodies in serum and muscle fluid of swine infected with 100, 300, 500 or 1000 oocysts. Vet Parasitol 2012; 190: 362-367.

17. Villena I, Durand B, Aubert D, Blaga R, Geers R, Thomas M, Perret $\mathrm{C}$, Alliot A, Escotte-Binet $\mathrm{S}$, Thébault A, Boireau $\mathrm{P}$, Halos L. New strategy for the survey of Toxoplasma gondii in meat for human consumption. Vet Parasitol 2012; 183: 203-208.

18. Sroka J, Wójcik- Fatla A, Zając V, Sawczyn A, Cisak E, Karamon J, Dutkiewicz J, Bojar I. Comparison of the efficiency of two commercial kits - ELFA and Western blot in estimating the phase of Toxoplasma gondii infection in pregnant women. Ann Agric Environ Med 2016; 23: 570-575. 
19. Rostami A, Karanis P, Fallahi S. Advances in serological, imaging techniques and molecular diagnosis of Toxoplasma gondii infection. Infection 2018; 25: 264.

20. Glor SB, Edelhofer R, Grimm F, Deplazes P, Basso W. Evaluation of a commercial ELISA kit for detection of antibodies against Toxoplasma gondii in serum, plasma and meat juice from experimentally and naturally infected sheep. Parasit Vectors 2013; 6: 85.

21. Meemken D, Tangemann AH, Meermeier D, Gundlach S, Mischok D, Greiner M, Klein G, Blaha T. Establishment of serological herd profiles for zoonoses and production diseases in pigs by "meat juice multi-serology". Prev Vet Med 2014; 113: 589-598.

22. Nam HW, Ahn HJ, Yang HJ. Pro-inflammatory cytokine expression of spleen dendritic cells in mouse toxoplasmosis. Korean J Parasitol 2011; 49: 109-114.

23. Kim TY, Joo IJ, Kang SY, Cho SY, Kong Y, Gan XX, Sukomtason K, Sukomtason K, Hong SJ. Recombinant Paragonimus westermani yolk ferritin is a useful serodiagnostic antigen. J Infect Dis 2002; 185: 1373-1375.

24. Gamble HR, Dubey JP, Lambillotte DN. Comparison of a commercial ELISA with the modified agglutination test for detection of Toxoplasma infection in the domestic pig. Vet Parasitol 2005; 128: 177-181.

25. Hill DE, Chirukandoth S, Dubey JP, Lunney JK, Gamble HR. Comparison of detection methods for Toxoplasma gondii in naturally and experimentally infected swine. Vet Parasitol 2006; 141: 9-17.

26. Lind P, Haugegaard J, Wingstrand A, Henriksen SA. The time course of the specific antibody response by various ELISAs in pigs experimentally infected with Toxoplasma gondii. Vet Parasitol 1997; 71: 1-15.

27. Basso W, Hartnack S, Pardini L, Maksimov P, Koudela B, Venturini MC, Schares G, Sidler X, Lewis FI, Deplazes P. Assessment of diagnostic accuracy of a commercial ELISA for the detection of Toxoplasma gondii infection in pigs compared with IFAT, TgSAG1-ELISA and Western blot, using a Bayesian latent class approach. Int J Parasitol 2013; 43: 565-570.

28. Dubey JP, Jones JL. Toxoplasma gondii infection in humans and animals in the United States. Int J Parasitol 2008; 38: 1257-1278.

29. Dzib-Paredes GF, Rosado-Aguilar JA, Acosta-Viana KY, OrtegaPacheco A, Hernández-Cortázar IB, Guzman-Marín E, JiménezCoello M. Seroprevalence and parasite load of Toxoplasma gondii in Mexican hairless pig (Sus scrofa) tissues from the Southeast of Mexico. Vet Parasitol 2016; 229: 45-49.

30. Jiang T, Gong D, Ma LA, Nie H, Zhou Y, Yao B, Zhao J. Evaluation of a recombinant MIC3 based latex agglutination test for the rapid serodiagnosis of Toxoplasma gondii infection in swines. Vet Parasitol 2008; 158: 51-56.

31. Lundén A, Lind P, Engvall EO, Gustavsson K, Uggla A, Vågsholm I. Serological survey of Toxoplasma gondii infection in pigs slaughtered in Sweden. Scand J Infect Dis 2002; 34: 362-365.

32. Dubey JP. Toxoplasmosis of Animals and Humans. 2nd ed. Boca
Raton, USA. CRC Press. 2016.

33. Opsteegh M, Langelaar M, Sprong H, den Hartog L, De Craeye S, Bokken G, Ajzenberg D, Kijlstra A, van der Giessen J. Direct detection and genotyping of Toxoplasma gondii in meat samples using magnetic capture and PCR. Int J Food Microbiol 2010; 139: 193-201.

34. Juránková J, Basso W, Neumayerová H, Baláž V, Jánová E, Sidler X, Deplazes P, Koudela B. Brain is the predilection site of Toxoplasma gondii in experimentally inoculated pigs as revealed by magnetic capture and real-time PCR. Food Microbiol 2014; 38: 167170.

35. Felin E, Näreaho A, Fredriksson-Ahomaa M. Comparison of commercial ELISA tests for the detection of Toxoplasma antibodies in the meat juice of naturally infected pigs. Vet Parasitol 2017; 238: 30-34.

36. Seo MG, Jang YS, Lee EM, Park NC, Kwak DM. Prevalence of antibodies to Toxoplasma gondii in cattle and pigs reared in eastern areas of Gyeongbuk province. Korean J Vet Serv 2009; 32: 131137.

37. Kim YH, Lee Jh, Ahn SK, Kim TS, Hong SJ, Chong CK, Ahn HJ, Nam HW. Seroprevalence of toxoplasmosis with ELISA and rapid diagnostic test among residents in Gyodong-do, Inchon city, Korea: a four-year follow-up. Korean J Parasitol 2017; 55: 247254.

38. Ortega-Pacheco A, Acosta-Viana KY, Guzman-Marin E, Uitzil-Álvarez B, Rodríguez-Buenfil JC, Jimenez-Coello M. Infection dynamic of Toxoplasma gondii in two fattening pig farms exposed to high and low cat density in an endemic region. Vet Parasitol 2011; 175: 367-371.

39. Hwang J, Gottdenker N, Oh DH, Lee H, Chun MS. Infections by pathogens with different transmission modes in feral cats from urban and rural areas of Korea. J Vet Sci 2017; 18: 541-545.

40. Alvarado-Esquivel C, Estrada-Malacón MA, Reyes-Hernández SO, Pérez-Ramírez JA, Trujillo-López JI, Villena I, Dubey JP. High prevalence of Toxoplasma gondii antibodies in domestic pigs in Oaxaca State, Mexico. J Parasitol 2012; 98: 1248-1250.

41. Herrero L, Gracia MJ, Pérez-Arquillué C, Lázaro R, Herrera A, Bayarri S. Toxoplasma gondii in raw and dry-cured ham: the influence of the curing process. Food Microbiol 2017; 65: 213-220.

42. Hill DE, Haley C, Wagner B, Gamble HR, Dubey JP. Seroprevalence of and risk factors for Toxoplasma gondii in the US swine herd using sera collected during the National Animal Health Monitoring Survey (Swine 2006). Zoonoses Public Health 2010; 57: 53-59.

43. Djokic V, Blaga R, Aubert D, Durand B, Perret C, Geers R, Ducry T, Vallee I, Djurkovic Djakovic O, Mzabi A, Villena I, Boireau P. Toxoplasma gondii infection in pork produced in France. Parasitology 2016; 143: 557-567.

44. Muñoz-Zanzi C, Tamayo R, Balboa J, Hill D. Detection of oocyst-associated toxoplasmosis in swine from southern Chile. Zoonoses Public Health 2012; 59: 389-392. 